\title{
Translation Strategies in Global News: What Sarkozy said in the Suburbs
}

SCAMMell, ClaiRe. 2018. Translation Strategies in Global News: What Sarkozy Said in the Suburbs. Stevenage: Palgrave Macmillan.

Reviewed by TAMBOLI RESHMA

Language plays an important role in human interaction. One misused or misinterpreted word and one might be a subject of controversy. News reporting plays a crucial role in such incidents. It's important to notice that 'how' does media present 'what' was said is much more important than 'what was said'. Here's where news agencies play a mediator's role. News travel worldwide through the news agencies and in Anna Rusconi's words, 'translators do the driving.' So while reporting global news, translation becomes second mediation and the translator- a second mediator. Words not translated accurately with its culture-specific meaning result in a translation blunder. Many translation blunders have embroiled politicians and world leaders in the controversy. Therefore news agencies adopt certain translation strategies in global news reporting.

Claire Scammell pinpoints the well-thought and deliberate ways of presenting 'what was said' chosen by news agencies in her book Translation Strategies in Global News. The book directs attention towards the relation between translation process and journalistic ideals. The author presents how culture-specific words are lost in translation and result in translation blunder with the example case study news event 'What Sarkozy said in suburbs.' Its main focus is on the strategies used in news translation. It dives deep into the study of strategies used, its impact on the overall process of translation and news reporting, problems with existing strategies and possible updates to overcome it. Furthermore, it 
explores the possibility of second level mediation in news translation.

The book is divided into eight chapters and each chapter has a title. All chapters except last one are similar in presentation style. Each Chapter starts with abstract and then followed by keywords, introduction to the topic of the chapter and the main topic that is divided into sub-points. References are provided at the end of each chapter. These eight chapters are drawn on the three-pointed model. Chapter one is introductory. Chapter two to seven states case study news event and its discourse. The last chapter concludes the whole subject of the book. The arrangement of the chapters is a linear one.

The first chapter gives an example of the famous translation blunder- 'What Sarkozy said in the 'suburbs' in 2005' which is also the case study news event for the book. A corpus of five English-language Reuters news reports of case study news event is presented in a table form. These reports are investigated throughout the book. Then the chapter states what the next chapters are about. Before starting to write about the exact point, author Claire Scammell gives the reader a fair idea of what to expect in each chapter. Chapter two informs how three big news agencies named Reuters, Agence France-Presse and Associated Press dominate the global media. Citing Tuchman, author Claire Scammell says that "the global agencies are, to a large extent, responsible for what we see and understand of that world" (p. 8). This chapter states how changes have occurred in the functioning of news agencies. It takes a look at the reasons behind increasing dominance of the global news agencies. It also states and discusses in detail the factors involved in the decline in global reporting. The author brings to attention the values of journalism which are objective and unbiased. Referencing Peterson, the author states the role 
of quotation in exercising these values. It studies the case news event reports in details.

Similarities between recontextualizing and domestication are pointed out in the third chapter. It also talks about the alternate terms - rewriting and trans-editing, used for translation in the news field. Then two translation strategies- 'foreignisation' and 'domestication' and debates around it are discussed in the third chapter. Arguments in favour of foreignisation by Venuti are referred. Counter-arguments by Pym are also stated. In the end, Claire Scammell propounds that "the criticism against Venuti seems to be directed mainly at the way arguments are packaged" (p. 26). Along with that, the author also provides with the information of news translation and the domestication norm. It is this chapter where the author has stated the scope of some degree of foreignisation in news translation. She rejects 'absolute foreignisation as an alternative to absolute domestication' (p. 29). Forth chapter dwells on the case study news event- 'what Sarkozy said in 'suburbs'. Three culturespecific words- 'banlieu, quartier and cite' in French language and its translation in the English language is noted with examples. It states the double mediation of quotation and culture in the news. This chapter also explores the scope of foreignisation in Reuters news agency as it is a leading news company. It studies the approaches used in Reuters corps reports. In the end, the author tries to attend a golden mean in translation strategy debate.

Chapter five explains the definition and use of 'strategy' within translation studies. A brief survey of methods applied in translation strategy is presented. Pedersen's strategies for rendering culture are given in this chapter. Different methods used in domestication and foreignisation are presented in the fifth chapter. Theoretically presented strategies in chapter five are applied to The Reuters corpus in the next chapter. A 
numerical survey of foreignising and domesticating strategies and its methods used in Reuters journalism is presented in the sixth chapter. A detailed study of SL oriented and TL oriented strategies used to translate culture-specific concepts in the Reuters corpus is given. This chapter also restates the translation anonymity involved in global news reporting. In the end, the author points towards Reuters' current approach of domestication in news translation and proposes the possibility of update in Reuter's handbook.

Finally, the seventh chapter proposes five updates that can bring a degree of foreignisation to the domestication strategy in news translation. Examples of original news segments are complemented with the updated foreignised segment. Every presented update is followed by a table that gives examples of the impact of a suggested update on Reuters reporting. This chapter explores the possibility of accurate translation of culture-specific concepts. Then the final and the eighth chapter summarises the conclusions of translation approaches used in global news. It concludes with the opinion of emphasizing the identification of correct translation strategies.

Translation Strategies in Global News is an informative and insightful book. In the very beginning, it clears that most of the news we read, is copied and not originally written ones. Points stated in the book are well-researched. Author has presented her ideas and points with just examples. Every chapter is complemented by notes and bibliographical references. Provided notes make it easy for a reader to understand the example better. Often, the book, which studies strategies and explores a possible solution to debates, has a risk of being complex in its language and style. This book is an exception to that. Its language is simple and the book is easyto-read. One can easily comprehend it. It's the most positive aspect of the book. Chapter-wise introduction prepares the 
reader for a focused study of the book. Claire Scammell has given justice in explaining French culture-specific concepts. Considering that she is an English - French freelance translator, the use of French news examples table is justified. Yet a single table of worldwide translated news ratio would add more insight to the topic.

The biggest success of this book is that it is a thoughtprovoking book. From the very beginning, it engages the reader's attention. While reading the book, one gets more curious about news translation policies, language led politics and its impact on the global political horizon. This book is useful to Translation Studies research students, translators and anyone who wants to work in news translation as it gives important insight into the field.

\section{References}

Rusconi, AnNA. Words Travel Worlds: Translators Do the Driving.

Online:

http://languageloveaffair.tumblr.com/post/146704804104/word s-travel-worlds-translators-do-the-driving

SCAMmell, Claire. 2018. Translation Strategies in Global News: What Sarkozy Said in the Suburbs. Stevenage: Palgrave Macmillan. 